\title{
On-Demand Post-Disaster Emergency Shelters
}

\author{
Mahasti Tafahomi \\ Research Lab, Shelterexpert.org, Delft 2611 NK, the Netherlands
}

\begin{abstract}
In post-disaster emergency shelter aid, various relief agencies and other actors with different backgrounds need to cooperate in a tremendously short amount of time and under very different circumstances. In this article, we describe a research project that develops and tests a new approach in which the demands for shelters in a specific situation are methodically connected with available, innovative and sustainable shelter solutions, a DSS (decision support system). The DSS is a digital tool that translates the gathered evidence on needs, solutions and location including long-term effects of shelter provision into advice for the provision of sustainable, integral broader shelter solutions and designs. The outcome is a set of characteristics for a DSS for the provision of on-demand emergency shelters. A DSS that meets these characteristics leads to the provision of sustainable shelters that meet the needs of the users and, therefore, have higher performance in long term.
\end{abstract}

Key words: Post-disaster, on-demand post-disaster shelters, sustainable shelter, emergency relief, innovation, tents, decision support system.

\section{Introduction}

\subsection{Post-Disaster Shelters}

Relief organizations including the International Red Cross and the UNHCR (United Nation High Commissioner for Refugees) have recently expressed a need for more variety when choosing shelters in the immediate aftermath of a disaster (Geneva, shelter meeting 2009 and 2010). When choosing or designing a post-disaster emergency shelter in a post-disaster emergency operation project, it is essential to connect the needs with the available shelter solutions and innovations for post-disaster emergency shelters in a specific situation. There is a need for on-demand provision of post-disaster emergency shelters and shelter items. Lessons learned from the earlier experiences and the earlier performed post-disaster shelter relief, accurate evidence gathering, assessments and the understanding of the whole process play an important role in this complex and hectic process.

Corresponding author: Mahasti Tafahomi, M.Sc., research fields: design and post-disaster emergency shelter aid. E-mail: info@shelterexpert.org.

\subsection{Decision Tool}

The increasing emphasis on innovation, resilience and preparedness in humanitarian actions, and the need for optimal intersectoral communication, lead to new approaches where data gathering and data analysis become major elements that affect the results of relief activities [1].

The recent initiatives to gather data on the needs directly from the beneficiaries after a disaster, using mobile phones, is an example of the inevitable role of new technologies in post-disaster emergency aid. Mobile phones are currently used by the beneficiaries to communicate the available solutions, to find one another and to communicate the needs. The LMMS (last mile mobile solutions) initiative uses mobile phones for gathering data and for training.

Connecting the gathered data to the available solutions for providing tailored aid (shelter) can be realized with a DSS (decision support system). The DSS is a tool that can function within a framework with performance standards. The needs are to be systematically connected to the available solutions. Objective decision making can be facilitated to enable the beneficiaries and the shelter experts, to choose the 
most optimal shelter solutions in each situation.

In addition, using the DSS addresses the transparency and accountability in post-disaster emergency aid that leads to a more sustainable process of shelter aid.

Investigation of the possibility of using a systematic method, such as a DSS, for providing on-demand shelters in immediate post disaster, can result in more sustainable post-disaster shelter designs, as tailored solutions mean less waste, optimal use of energy and materials and less transportation costs.

\section{Sustainable Post-Disaster Emergency Shelters}

\subsection{Needs and Solutions}

Stainable development is development that meets the needs of the present without compromising the ability of future generations to meet their own needs according to the report "Our Common Future" [2].

According to Corsellis and Vitale [3], a "shelter" is a habitable covered living space, providing a secure and healthy living environment with privacy and dignity to those within it. In specific case of post-disaster shelter aid, in many occasions, the shelters are used for years, even for generations, while according to the international protocol, maximal use of an emergency shelter ought to be between 18 and 36 months. The necessity of semi-permanent shelters is indicated by experiences as in Darfur and Bam. In addition, the transformation of the emergency shelters into transitional and permanent habitats leads to more sustainable shelters and optimal use of materials.

\subsection{Long-Term Effects of Post-Disaster Emergency Aid}

Interviews with relief specialists as Graham Saunders, head of the IFRC (International Federation of Red Cross and Red Crescent Societies) and United Nations, report as Pakistan 2004 earthquake suggests that the first 24 to $48 \mathrm{~h}$ are crucial for saving lives. Enduring $24 \mathrm{~h}$ without shelter can be life-threatening in extreme climatic conditions, which may include severe cold, high altitudes, extreme heat or exposure to dust storms. For a large-scale emergency, shelters are often delivered internationally from pre-positioned stockpiles. In the first week, aid packages including shelter items are requested based on initial assessments and consultation. A pipeline for aid is then set up. Immediate needs are to be met in this phase.

The shelters provided in the immediate phase after a disaster (post-disaster emergency shelters) have long-term effect on the living conditions. The recent focus on the long-term effects of shelter and the strategy of using disasters as opportunities to improve people's living conditions in a sustainable manner has resulted in greater emphasis on transitional housing solutions [4].

We need to bring together needs and solutions in the immediate aftermath of a disaster, in a manner that the long-term effects are positive, to provide sustainable post-disaster shelters. Implementing the local and the proven solutions can contribute to more efficiency and optimal post-disaster emergency shelter aid [5]. Post-disaster emergency shelters meet the immediate shelter needs of the beneficiaries. However, the provided aid can have impact on the long-term way of life of the receiving community [6]. Examples are the introduction of solar lanterns, green sanitation facilities and awareness of how to cut wood for cooking without destroying the forest $[7,8]$.

The ability to provide optimal and immediate post-disaster shelter while, simultaneously, taking into account the long-term effects and factors such as sustainability, cultural acceptance, costs reduction and interaction with beneficiaries are to be incorporated in the DSS. The emphasis is on meeting the immediate needs and respecting human dignity in a hectic situation [9].

\subsection{Data/Evidence}

Reliable data gathering, data storage, data analysis, 
data connection and data security are the key words in the DSS. As service calls to external sources can be realized, data gathering is not limited to the data that the DSS can gather. However, realizing service calls to external data gathering systems needs additional reliability and security steps and causes that the DSS is dependent of external factors for optimal functioning.

Master data, the structural key information for the decision making process, are gathered and administrated by the data manager.

Currently, the DSS performs service calls to the KNMI (Koninklijk Nederlands Meteorologisch Instituut) and Google maps. The service calls can be expanded. Regarding the solutions, data gathering involves data from the materials and solutions that are available on the market, including local resellers.

\subsection{Evidence Gathering and Implementation}

Optimal choice of shelter solutions in post-disaster emergency situations depends on deep understanding of needs, contexts of the needs, practical knowledge of the available solutions and smart strategies to connect the two optimally [10].

In this article, we investigate a new approach in which the needs for shelters in a specific situation are methodically connected with available and innovative shelter solutions by using a DSS.

Evidence of needs can be submitted both by the beneficiaries and relief specialists as NGOs (non-government organizations) and the UN. The solutions can be entered by local or international suppliers. The questions asked by the DSS can be adapted to each type of user.

Fig. 1 presents a summary of the first steps in the interface of the current DSS.

The DSS presents the specific questions for each type of user. The following steps will then be performed:

(1) Log on: type of user;

(2) A: enter product specifications, or B: enter new disaster;

(3) B: select the disaster location (continent, country or region) and disaster type;

(4) B: enter disaster specifications (different questions for beneficiaries and relief specialists);

(5) B3: the DSS presents the location data and a link to relevant sites as Google maps;

(6) B: the DSS provides a first analysis of the disaster and a first set of advice;

(7) B: based on this advice and personal judgment, the user selects the shelter specifications;

(8) B: the DSS presents a list of five shelters that meet the specifications the most with ranking;

(9) B: choose the cheapest or the fastest;

(10) B: the DSS produces a final report of the number and price for the shelters.

\subsection{Final Report}

Currently, writing reports is one of the tasks of senior shelter relief specialists. Writing reports offered shelter aid is a time consuming administrative activity

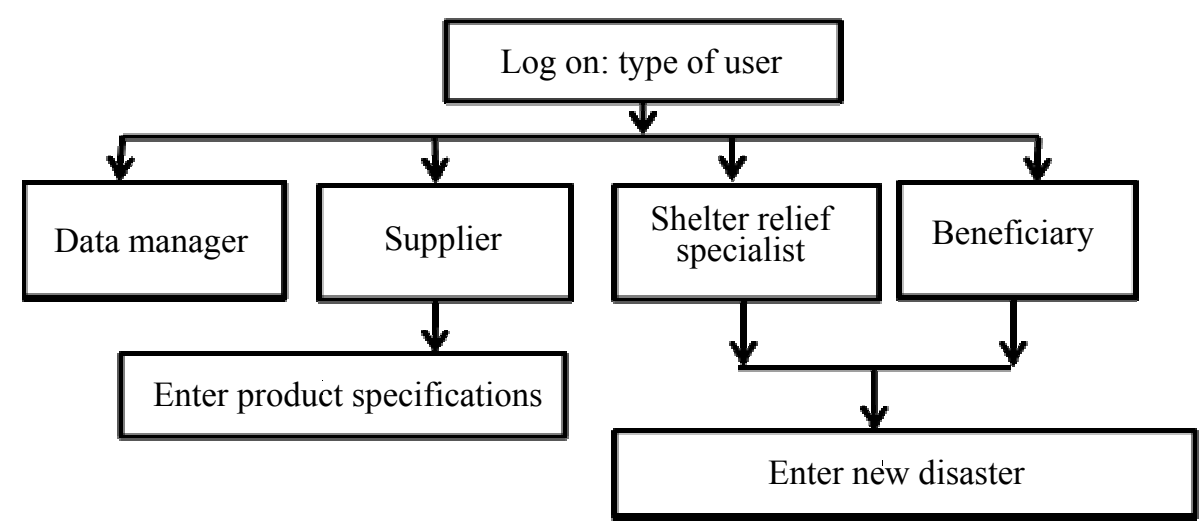

Fig. 1 Log on and user identification. 
needed to fulfill the accountability aspect as well as documentation of the experiences.

In addition to advice for the optimal shelter, the DSS produces a final report of the offered shelters. The current DSS provides three chapters:

(1) problems caused by the disaster;

(2) general advices as: earlier disasters/lessons learnt/advice in shelter related sectors;

(3) report of the provided shelters - shelter advice including the costs.

\section{Shelter Solutions}

\subsection{Sustainable Post-Disaster Emergency Shelters}

Regarding the total shelter solutions, when a suitable shelter program/project is not available, an innovative design can be suggested by the DSS.

Successful choice of shelter solutions in post-disaster emergency situations depends on deep understanding of the needs, contexts of the needs, practical knowledge of the available solutions and smart strategies to connect the two optimally.

Post-disaster emergency shelter designers are, as any other designer, concerned with the ecological, social, cultural and spatial application of technologies to meet specific human needs after each disaster and in each location. The choice for an on-demand designed shelter contributes to optimal post disaster shelter relief process and sustainable post disaster emergency shelters.

\subsection{Meeting the Standards}

Around 2000, the criticism from the donating population on the spending and quality of shelter relief after disasters began to rise. The suggestions were made that the assessments made by relief specialists in occasions exaggerated the amount of beneficiaries and resulted in exaggerated amount of needed relief items including shelters. Lack of transparency and accountability resulted in rising of the assumptions of possible corruption in the relief system. In addition, the provided aid, including shelter aid, did not meet the needs of the beneficiaries.

In response, the UN Under-Secretary-General for Humanitarian, Affairs Jan Egeland, commissioned the HRR (Humanitarian Response Review) in 2005 to address failures in the international response to humanitarian crises. The review [11] found that the performance of the UN humanitarian coordination structure depended too much on the personal qualities and diplomatic skills of the resident coordinator/humanitarian coordinator and that the speed, quality and effectiveness of humanitarian responses were inadequate and that no common basis existed for assessing and comparing levels of need. Funding levels and methods were also found to be inadequate. The HRR report aimed to address weaknesses relating to accountability, predictability and reliability by the cluster approach. Organizations were nominated to act as leaders in areas where humanitarian response gaps had been identified. Under this approach, these organizations would then become responsible for specific areas or clusters.

Following the recommendations of the review, the cluster approach was proposed as a way of addressing gaps and strengthening the effectiveness of humanitarian response through building partnerships. Moreover, the cluster approach aims to ensure predictability and accountability in international responses to humanitarian emergencies by clarifying the division of labor among organizations and better defining their roles and responsibilities within the different sectors of the response. It is about making the international humanitarian community more structured, accountable and professional, so that it can be a better partner for host governments, local authorities and local civil society. The IASC (Inter-Agency Standing Committee) has designated global cluster leads in 11 areas of humanitarian activity.

Next to the cluster approach, the report suggested to provide humanitarian coordinators, who are selected 
and trained well in advance of their assignment, with the appropriate tools in order for effective systemic coordination to become the norm.

UN relief organizations and specialists acknowledge that adequate shelter is vital for saving thousands of lives. In most cases, financial resources are the decisive factor determining the quality and quantity of the available shelters.

The first initiative for standardization of sheltering process, the sphere, was launched in 1997 by a group of humanitarian NGOs and the Red Cross and Red Crescent movement. They formulated a humanitarian charter and identified minimum standards to be attained in disaster assistance, in each of five sectors of aid: water supply and sanitation, nutrition, food aid, shelter and health services. This process led to the publication of the Sphere Handbook in 2000. The Sphere Project is a voluntary initiative that aims to improve the quality of humanitarian aid and the accountability of humanitarian response. The Sphere Project was to develop a common framework and improve accountability for humanitarian aid. The Sphere Project is continuously being up to dated and developed. The humanitarian community mostly uses Sphere standards inconsequently. In some cases, Sphere indicators and standards have been dismissed, as in case of Pakistan where relief organizations decided that "Sphere standards could and would not be met". An insufficient shelter supply was the motive not to meet the Sphere-approved quality levels in order to provide aid for more affected population.

Currently, various guidelines for shelters are available. Each organization has specific standards as the UNHCR Handbook and the IFRC Catalogue.

To provide on-demand post-disaster shelters, tailored for each situation, and to meet the needs of the beneficiaries, we need performance standards in addition to the general basic and product standards formulated within the Sphere Project and the available handbooks.

In the complex environment of post-disaster shelter relief, the task of creating optimal designs needs a systematic framework. The framework should take the following aspects into account:

- context-sensitivity;

- crisis-sensitivity;

- "performance standard" paradigm.

Performance standards lead to flexible design environment that leaves room for flexible sustainable shelter designs [10].

\subsection{On-Demand Sustainable Post-Disaster Emergency Shelters}

Designing a post-disaster emergency shelter with the aid of a DSS needs adaptive design thinking. The basic design is to be flexible.

For this reason, we developed a basic design for a sustainable shelter that can be realized using the parameters of a DSS and can be adapted to each specific situation with the aid of the DSS. A central column in the shelter can include additional part solutions as energy, water and sanitation.

Fig. 2 illustrates two possible shapes of the designed shelters. The frame and the central column provide a freedom for designs and flexibility to create culturally accepted shapes for the shelters. This means more acceptance and longer use of the shelters, thus, more sustainable shelters.

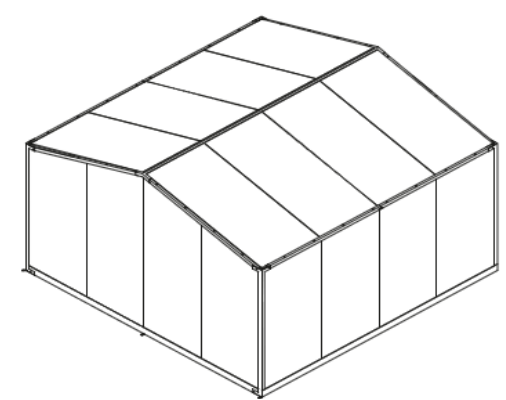

(a)

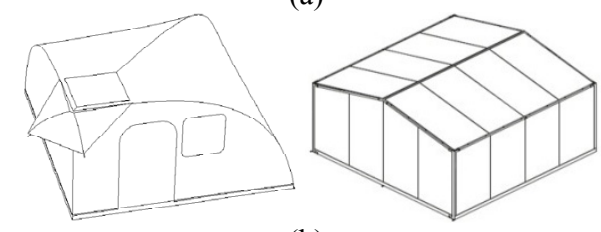

(b)

Fig. 2 Designed shelters: (a) transitional; (b) rapid response. 
Usage of local materials, energy and cost effective designs are the consequences of this approach.

\subsection{Total Concept}

The design contains a central column that is a part of the construction, the construction and the skin including the floor.

Depending on the needs and the available solutions, the content of the central column will be chosen. Sanitation, heating and cooking facilities can be included in the column. There are various options for the skin and the construction. Two examples are:

- transitional solution: with construction profiles and the possibility of filling the surface with panels and extra accessories with the locally available materials (Fig. 2a);

- the rapid response: lightweight emergency solution with flexible tubes as construction and lightweight fabric (Fig. 2b). The flexible elements can be replaced by aluminum profiles or locally available materials for long-term usage.

As the central column provides flexible content, tailored solutions for each post-disaster situation can be offered. Fig. 3 illustrates the position of the column in the shelter.

Based on the gathered evidence on needs and solutions, the DSS can provide advice for tailored shelter solutions. The advice can be materialized with this shelter design approach. This approach will lead to more sustainable and tailored shelter solutions that meet the needs of the beneficiaries the most (Fig. 3).

The DSS can provide detailed advice regarding used materials and insulation. An optimum will be calculated and presented in diagrams as Fig. 4 shows.

To meet the specific needs of the beneficiaries after each disaster, the DSS needs to provide advice for shelter parts and integral shelter designs. Water, sanitation and energy can be included in the shelter advice. Fig. 5 illustrates the design for the central water and sanitation unit, developed in this research project.

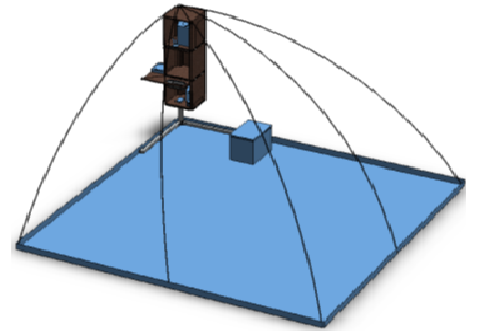

Fig. 3 The position of the column in the shelter construction.

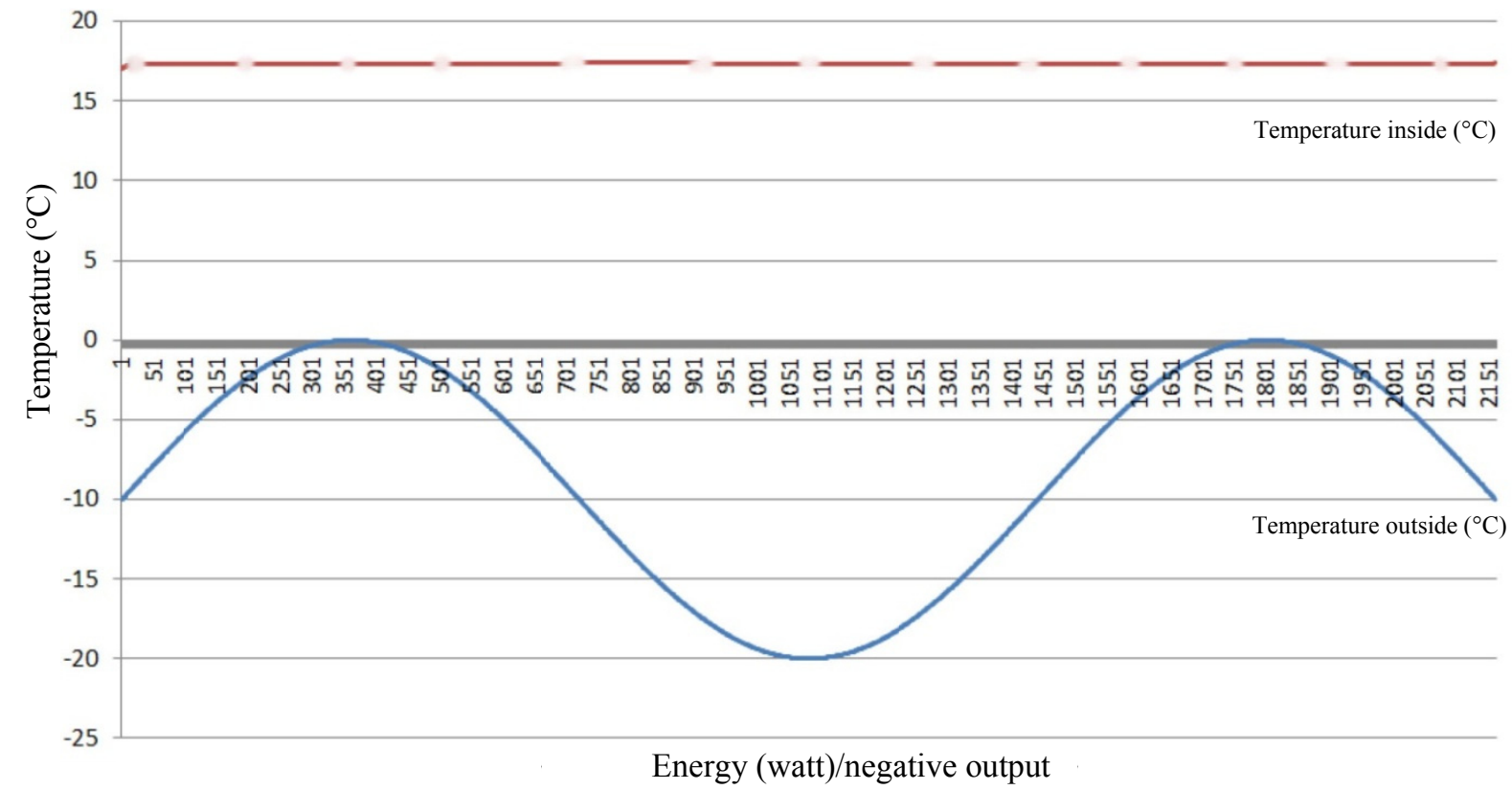

Fig. 4 Realizing constant temperature inside in various outside conditions.

Source: TonnyGrimberg, Saxion. 

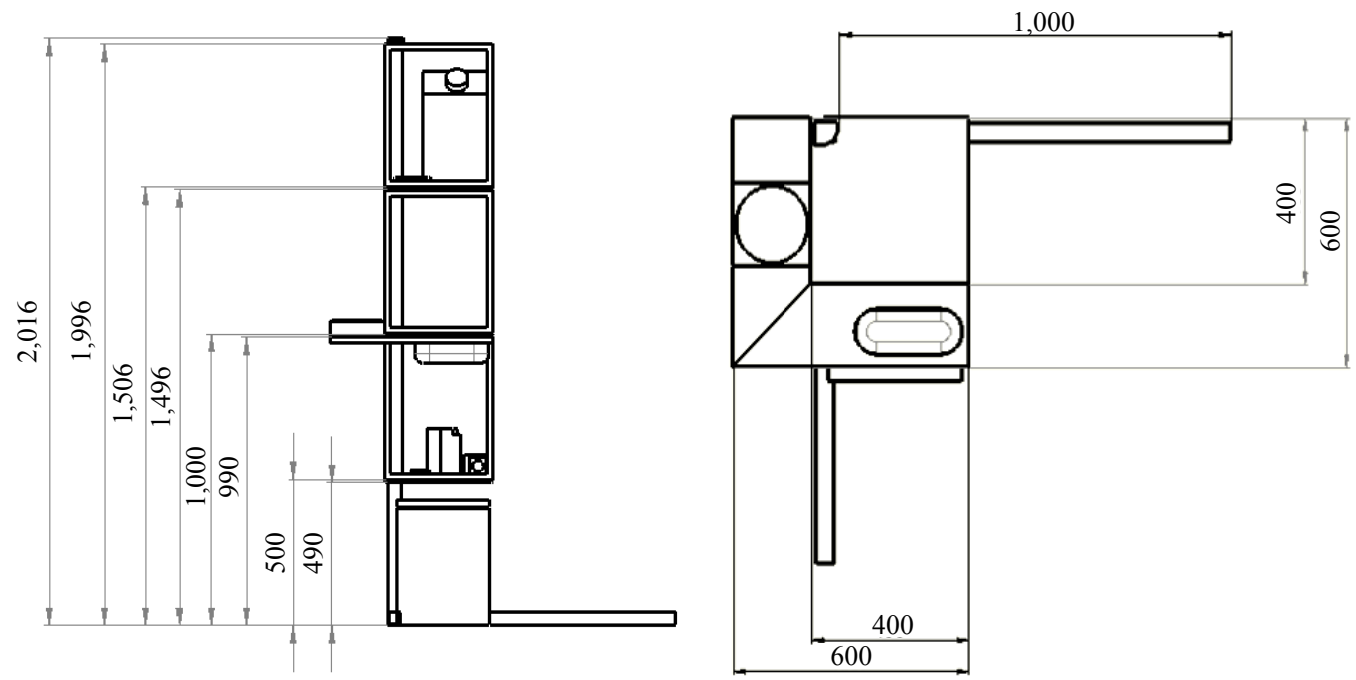

Fig. 5 The central column which can include energy, water and sanitation units.

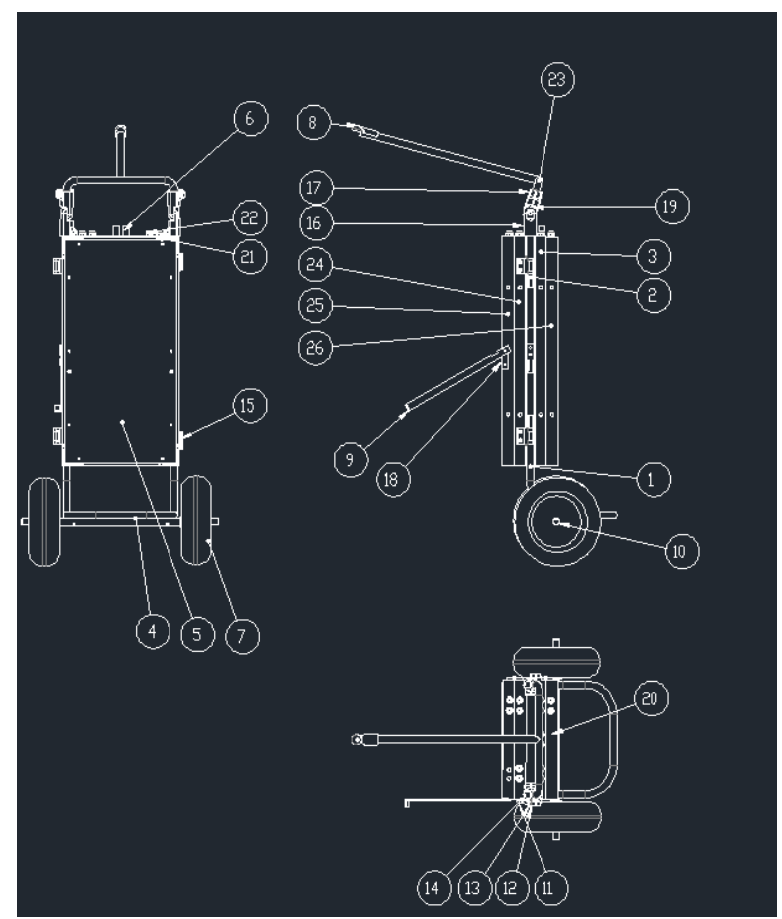

Fig. 6 The energy section which can be delivered as a separate unite (Johan Kok, Iindustrialdesign.nl, designer of this concept).

1: square tube; 2: U-profile; 3: solar panel; 4: axis tube; 5: cover plate; 6: connector; 7: wheel; 8: bullet; 9: leg; 10: shaft; 11: offset 1; 12: offset 2; 13: pin; 14: intermediate plate; 15: hinge plastic; 16: 29024_30; 17: 29026_30; 18: intermediate plate for the leg; 19: part 16; 20: profile; 21: M16-(08)-Std_Body; 22: M16-CAP; 23: rod; 24: panel foldable; 25: panel left; 26: panel right.

An energy unit that can be adapted to the needs in each situation and meet the maintenance criteria is being investigated currently. Fig. 6 illustrates the basic mobile energy unit that is developed and tested. We need to keep in mind that the choice of water, sanitation and energy facilities is made by shelter experts. The task of the DSS is the provision of advice, by connecting the evidence on needs, location and solutions and presenting the possible solutions that meet the needs of the beneficiaries the most for each situation.

Regarding energy provision, the advice provided by the DSS is to be based on long-term effects of the usage of wood that results in deforestation, versus durable energy sources as solar energy or the fire sensitivity when using kerosene versus the usage of alternative energy sources that are currently less cost effective and need maintenance and technical know-how. The latter can mean educating the local population and growing local economy.

\section{Conclusions}

This research project can be summarized in a set of characteristics for a DSS for post-disaster emergency shelter aid. The optimal DSS for post-disaster emergency shelters has the ability to provide uniform advice.

The test in this research project indicates that users including relief specialists and the beneficiaries need to believe in accuracy and reliability of the advice provided. In addition, participation of the users in the 
creation of the DSS, a flexible framework and a reliable and secure infrastructure are needed for a DSS that will be used by the involved parties.

According to our findings, a DSS that meets these characteristics leads to the provision of shelters that meet the needs of the users and, therefore, have higher performance in long term.

The DSS is a digital tool that translates the gathered evidence on needs, solutions and location including long-term effects of shelter provision into advice for the provision of sustainable, integral broader shelter solutions and designs and produces reports.

The current DSS that is a prototype needs to be optimized and further developed, in cooperation with the users, e.g., the beneficiaries, the shelter experts, the designers, and suppliers.

In decision making, when choosing post-disaster shelter items, as well as designing post-disaster shelters, a more integral viewpoint and constantly tuned data result in better decisions or designs. In the specific case of post-disaster emergency shelters, an integral approach from clothing and sanitation to water, energy and construction results in more tailored solutions, which can save time, costs and, as a result, save more lives. As, for instance, in cold climates, providing hats/winter-caps can result in less need for heating in the shelter. There is a need for a design for a tool that can provide uniform advice for tailored, on-demand integral combination of the available preferably local shelter solutions.

Decision support systems are known tools in aviation and as design tools. In post-disaster emergency aid, however, such a tool does not exist.

This research project presents a set of characteristics for a DSS for on-demand post-disaster emergency shelter aid. The optimal DSS for post-disaster emergency shelters has the ability to provide uniform advice.

In addition to a flexible framework, an adaptive way of thinking by the relief specialists is needed to provide on-demand post-disaster shelters. The pipelines that are currently set up and are seen as a routine are to be re-thought. In addition, relief specialists may need time to get used to a new approach. The DSS can be used as a training tool, as the DSS can make a selection from the existing solutions.

The optimal DSS can make a selection of existing shelters based on relevance to the situation: ranking in the needed specifications, the priorities of the users as indicated in earlier steps. From the most suitable shelters, the cheapest or the fastest options can be selected. The cheapest and the fastest solutions will be specified by the amount of time and the difference in price. The user can choose the desired balance between time saving and optimal pricing using this information.

A set of rules has to be created in addition to the current rules. The system has to check the percentage of requirements that a shelter meets according to the selection rules. If a shelter fits for $99 \%$, and if no solution fits for the full $100 \%$, or if the shelter is significantly cheaper than the one with the full $100 \%$, then the shelter will appear in the solutions screen. The user can decide whether some requirements are too important to ignore or to accept the shortcomings of a certain shelter. As the DSS provides the possibility to return to earlier steps, the user can choose to return to previous steps and adjust the needed shelter specifications or continue and follow the advice provided by ranking.

In both cases of choosing from the existing solutions or designing on-demand shelters, the DSS needs data accuracy, data security, securing objectivity and transparency as well as infrastructure reliability and accessibility.

The tests in this research project indicate that participation of the users in the creation of the DSS, a flexible framework and performance standards, are needed for a DSS that will be used by the involved parties.

The optimal DSS is a digital tool that translates the gathered evidence on needs, solutions and location 
including long-term effects of shelter provision into advice for the provision of sustainable, integral broader shelter solutions and designs.

The ability to produce final reports is a key factor to provide transparency and to save time. The purchases and motivation for decisions are presented in the final report automatically.

The necessity of standards for stimulating transparency and exchangeability in the sheltering process and, therefore, increasing the efficiency of the shelter relief is recognized by the international community. However, standards are yet to be formulated in a way that stimulates innovation, flexibility, market transparency and improves the compatibility of various systems.

A post-disaster emergency shelter is more than a roof above the head. Aspects as camp design, rubble management, waste management and logistics are to be encountered in the design and selection process of a post-disaster emergency shelter. The DSS can provide assistance to the experts in the field and cannot replace relief specialists.

\section{References}

[1] Architecture for Humanity, Design Like You Give a Damn, Metropolis Books, New York, 2006.

[2] Our Common Future, Brundtland report, Oxford University Press, UK, 1987.

[3] T. Corsellis, A. Vitale, Transitional Settlement: Displaced Populations, Oxfam Publishing, UK, 2005.

[4] J. Ashmore, J. Fowler, J. Kennedy, Shelter Projects, UN-Habitat, 2008.

[5] F. Cuny, Shelter Documentation, UN Archive, 1972.

[6] I. Davis, Shelter after Disaster, Oxford Polytechnic Press, UK, 1978.

[7] ICRC/IFRC (International Federation of Red Cross and Red Crescent Societies/International Committee of the Red Cross), Catalogue 2002, ICRC, Geneva, 2012.

[8] Procurement Catalogues and Specifications, IAPSO (Inter-Agency Procurement Services Office), 2012.

[9] J. da Silva, Lessons from Aceh: Key Considerations in Post-Disaster Reconstruction, Practical Action Publishing, UK, 2010.

[10] M. Tafahomi, T.M. Egyedi, Defining flexible standards for post-disaster emergency sheltering, in: Proceedings of 13th EURAS (European Academy for Standardization) Workshop, Sweden, 2008, pp. 255-264.

[11] Humanitarian Response Review, OCHA (United Nations Office for the Coordination of Humanitarian Affairs), 2005. 